\title{
A Short Description on Transrectal Modality- Gray Scale \& Power Doppler Ultrasonography in Detecting Prostate Cancer

\author{
Islam $\mathrm{S}^{1 *}$, Islam $\mathrm{T}^{2}$, Khatun $\mathrm{H}^{3}$, Rahman $\mathrm{A}^{4}$
}

\begin{abstract}
${ }^{1}$ Md. Saiful Islam, Associate, Professor, Department of Radiology and Imaging, Rajshahi Medical College, Rajshahi, Bangladesh
${ }^{2}$ Md. Tarikul Islam, Assistant Professor, Department of Burn \& Plastic Surgery, Khulna Medical College Hospital, Khulna, Bangladesh

${ }^{3}$ Halima Khatun, Junior Consultant, Department of Obstetrics \& Gynaecology, Rajshahi Medical College Hospital, Rajshahi, Bangladesh

${ }^{4}$ Anisur Rahman, Assistant Professor, Department of Radiology and Imaging, Rajshahi Medical College Hospital, Rajshahi, Bangladesh
\end{abstract}

DOI: $10.36347 /$ sjams.2020.v08i12.030

| Received: 09.11.2020 | Accepted: 22.11.2020 | Published: 26.12.2020

*Corresponding author: MD. Saiful Islam

\section{Abstract}

Original Research Article

Introduction: Prostate cancer rarely causes symptoms early in the course of the disease because the majority of adenocarcinomas arise in the periphery of the gland, distant from urethra. The presence of symptoms as a result of prostate cancer suggest a locally advanced or metastatic disease. The lesion turns into advanced stage cancer due to accurate early detection. Aim of the study: To observe the specificity, accuracy both the transrectal sonographic modality-gray scale (TRUS) and Power Doppler ultrasonography in detecting prostate cancer. Methods: This was an observational study and was conducted in Urology Department of Bangladesh Institute of Research and Rehabilitation of Diabetes, Endocrine and Metabolic Disorders (BIRDEM), Bangabandhu Sheikh Mujib Medical University (BSMMU) and Dhaka Medical College hospital (DMCH), Bangladesh during the period from July 2005 to June 2007. 36 patients were included in the study. Statistical analysis of the results was done by computer software devised in the statistical packages for social scientist (SPSS-10) and MS excel-16. Result: In total 36 patients for study the validity found in gray scale TRUS were evaluated by calculating sensitivity $75.0 \%$, specificity $18.8 \%$, accuracy $50.0 \%$, positive and negative predictive values were $53.6 \%$ and $37.5 \%$ respectively and the validity found in Transrectal Power Doppler sonography was evaluated by calculating sensitivity $90.0 \%$, specificity $75.0 \%$, accuracy $83.3 \%$, positive and negative predictive values were $81.8 \%$ and $85.7 \%$ respectively. Conclusion: To reduce the rate of prostate cancer detection of the prostate lesion is much more important. As the histopathological diagnosis of the present study significantly correlate with both gray scale TRUS and transrectal Power Doppler findings as well as the validity tests are almost identical as observed by other researchers of different study, it can be concluded that transrectal Power Doppler ultrasonogram is useful diagnostic modality in the discrimination of benign and malignant lesions in the prostate.

Keywords: Prostate Cancer, Transrectal Modality, Gray Scale, TRUS, Power Doppler.

Copyright ( $(2020$ The Author(s): This is an open-access article distributed under the terms of the Creative Commons Attribution 4.0 International License (CC BY-NC 4.0) which permits unrestricted use, distribution, and reproduction in any medium for non-commercial use provided the original author and source are credited.

\section{INTRODUCTION}

Prostate cancer rarely causes symptoms early in the course of the disease because the majority of adenocarcinomas arise in the periphery of the gland, distant from urethra. The presence of symptoms as a result of prostate cancer suggest a locally advanced or metastatic disease. Growth of prostate Cancer into the urethra or bladder neck can result in obstructive (e.g. hesitancy, decreased force of stream, intermittency) and irritative (e.g. frequency, nocturia, urgency, urge incontinence) voiding symptoms. Additional symptoms may include bone pain or pathological fractures related to bone metastases, uraemia due to distal ureteric infiltration, local haemorrhage due to necrosis of the neoplasm or to prostatic fibrinolysin activity and rarely rectal bleeding or general haemorrhage due to release of large amounts of prostatic fibrinolysin. The routine uses of digital rectal examination (DRE) and prostate specific antigen (PSA) testing in asymptomatic men as a means of reducing prostate cancer mortality by earlier detection and treatment remains controversia [1]. Historically, almost every imaging technique has been applied to the examination of prostate. The use of ultrasonogram (USG) for the evaluation of prostatic carcinoma has been widely published. In trans abdominal scanning prostatic carcinoma most often demonstrates a hypoechoic area within the peripheral zone, which can however also be seen in a variety of benign disorders. The prostatic cancer can appear echogenic or iso echoic [2]. Small tumours \& sometimes advanced tumours are very difficult to detect as the entire peripheral zone may be involved and transabdominal sonography does not have better spatial 
resolution for identification of the lesion. Currently available methods for the early detection of prostate cancer include DRE, transrectal ultrasonogram (TRUS). Transrectal Power Doppler imaging is likely to contribute to the better characterization of hypoechoic lesions in the peripheral zone [3]. Transrectal Power Doppler is more sensitive to slow flow and is less angle dependent than TRUS. However, the positive detection rate in those with positive transrectal ultrasonography (TRUS) findings with both positive hypoechoic lesions on gray scale TRUS and increased vascularity on color Doppler images increased to $71 \%$ [4]. On the other hand, the main emphasis of prostate examinations with transrectal Power Doppler ultrasonography has long been the differentiation of prostate cancer from benign processes such as benign prostatic hyperplasia (BPH) and prostatitis by focusing on the tumour vascularity, rather than investigating the capability of the modalities to detect the changes in the vascular architecture secondary to the aforementioned disease processes [5].

The study aims to observe the specificity, accuracy both the transrectal sonographic modality-gray scale (TRUS) and Power Doppler ultrasonography in detecting prostate cancer.

\section{OBJECTIVES \\ General Objective}

- To observe sensitivity, accuracy, positive and negative predictive values of transrectal sonographic modality- gray scale \& Power Doppler sonography in the detection of prostatic cancer

\section{Specific Objective}

- To elucidate the correlation of transrectal Power Doppler findings with histopathological diagnosis of prostate lesions.

- To elucidate the correlation of gray scale TRUS findings with histopathological diagnosis of prostate lesions.

\section{Methodology \& Materials}

This was an observational study conducted in Urology Department of Bangladesh Institute of Research and Rehabilitation of Diabetes, Endocrine and Metabolic Disorders (BIRDEM), Bangabandhu Sheikh Mujib Medical University (BSMMU) and Dhaka Medical College hospital (DMCH), Bangladesh during the period from July 2005 to June 2007. The study was attempted on 52 male patients aged 40-70 years. They were suspected of having prostate cancer clinically and referred to the Radiology and Imaging department of BIRDEM for proper evaluation of prostate, whether benign or malignant by transrectal sonography before treatment planning \& further management. During transrectal gray \& Power Doppler sonographic examination ten of these patients were diagnosed normal and confirmed by follow up clinical and biochemical findings and were excluded from the study group Another two cases found to have rectal or anal stricture were also excluded from the study group. Four patients were excluded from the study as dropout cases. Finally, 36 patients were included in the study. The transrectal sonography (TRUS) examination was first performed by the investigator which was then subsequently confirmed by a skilled radiologist of the department of Radiology and Imaging of BIRDEM by studying the morphological pattern of the lesion along with their blood flow characteristics and resistance index (RI). The lesions were discriminated as benign or malignant before treatment. Tissue of prostate of all 36 patients either by biopsy or after prostatectomy operation were sent to the respected pathology departments for histopathological diagnosis. Histopathological diagnosis of each case was correlated with transrectal Power Doppler findings and transrectal gray scale ultrasonography findings. Data were collected from primary sources studying the clinical history, physical examination, biochemical finding. TRUS gray scale and Power Doppler findings, spectral analysis, that is, RI and, finally, tissue diagnosis by histopathology were recorded. All the relevant collected data were compiled on a master chart first, then organized by using scientific calculator and standard statistical formula. Percentage was calculated to find out the proportion of the findings. Further statistical analysis of the results was done by computer software devised in the statistical packages for social scientist (SPSS-10) and MS excel-16.

\section{RESULT}

In the study, the patients were divided included into three age groups. The age ranged from 45 to 70 years and the maximum patients were found in the age group of 60-70 years. The mean age was 56.7 years with standard error of mean (SE) \pm 1.7 years in benign lesions whereas in malignant lesions the mean age was 59.6 years with standard error of mean (SE) 1.4 years according to histopathological findings (Figure-1). The patients having prostatic lesions suspected as malignant benign by gray scale TRUS were correlated with histopathological diagnosis following collection of reports from the respective cases. Out of the 36 cases $20(55.6 \%)$ cases were malignant and $16(44.4 \%)$ cases were benign in histopathological findings. Of the total 36 cases, 28(77.87\%)) cases were suspected as malignant and rest o $8(22.2 \%)$ cases were suspected as benign in gray scale TRUS. Among the 28 cases, which were suspected as malignant by gray scale TRUS, 15 cases were malignant and 13 cases were found to be benign in histopathological examination. On the other hand, 5 cases were found as malignant and 3 cases were found as benign in histopathology among the suspected benign cases, which were diagnosed by gray scale TRUS (Table-1). The validity of gray scale TRUS were evaluated by calculating sensitivity $75.0 \%$, specificity $18.8 \%$, accuracy $50.0 \%$, positive and negative predictive values were $53.6 \%$ and $37.5 \%$ respectively (Figure-2). The patients having prostatic lesions 
suspected as malignant or benign by transrectal Power Doppler sonography were correlated histopathological diagnosis following collection of reports from the Transrectal respective cases. Out of the 36 cases $20(55.6 \%)$ cases were malignant and $16(44.4 \%)$ cases were benign in histopathological findings. Of the total 36 cases, $22(61.1 \%)$ cases were suspected as malignant and rest of the 14(38.9\%) cases were suspected as DET in transrectal Power Doppler sonography. Among the 22 cases, which were suspected as benign in transrectal Power Doppler. Among the 22 cases, which were suspected as malignant by Power Doppler ultrasonography, 18 cases were malignant and 4 cases were found to be benign in histopathological examination. On the other hand, 2 cases were found as malignant and 12 cases were found as benign in histopathology among the suspected 14 benign cases, which were diagnosed by Transrectal Power Doppler ultrasonography (Table-2). The validity of Transrectal Power Doppler sonography was evaluated by calculating sensitivity $90.0 \%$, specificity $75.0 \%$, accuracy $83.3 \%$, positive and negative predictive values were $81.8 \%$ and $85.7 \%$ respectively (Figure-3).

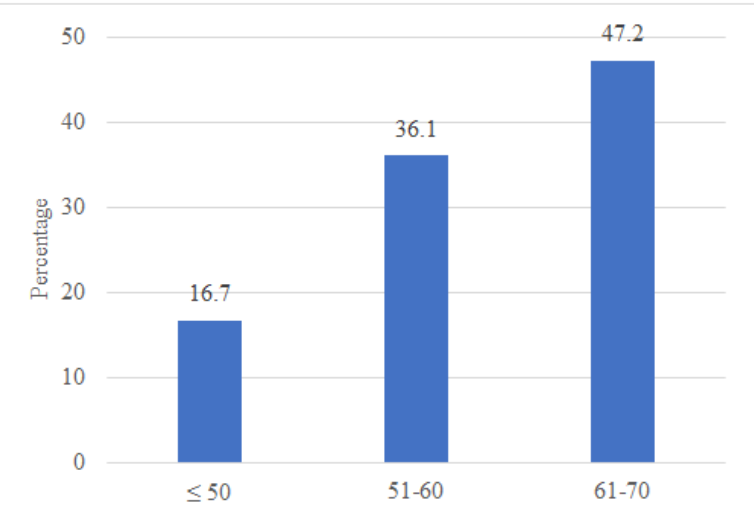

Fig-1: Bar diagram showing the age distribution of patients $(\mathbf{N}=36)$

Table-1: Gray scale TRUS and histopathological correlation of prostatic lesions $(n=36)$

\begin{tabular}{|l|l|l|}
\hline \multirow{2}{*}{ Gray scale } & \multicolumn{2}{|l|}{ Histopathological diagnosis } \\
\cline { 2 - 3 } & + ve for Malignancy & - ve for Malignancy \\
\hline Suspected for Malignant & 15 & 13 \\
\hline Suspected for benign & 5 & 3 \\
\hline
\end{tabular}

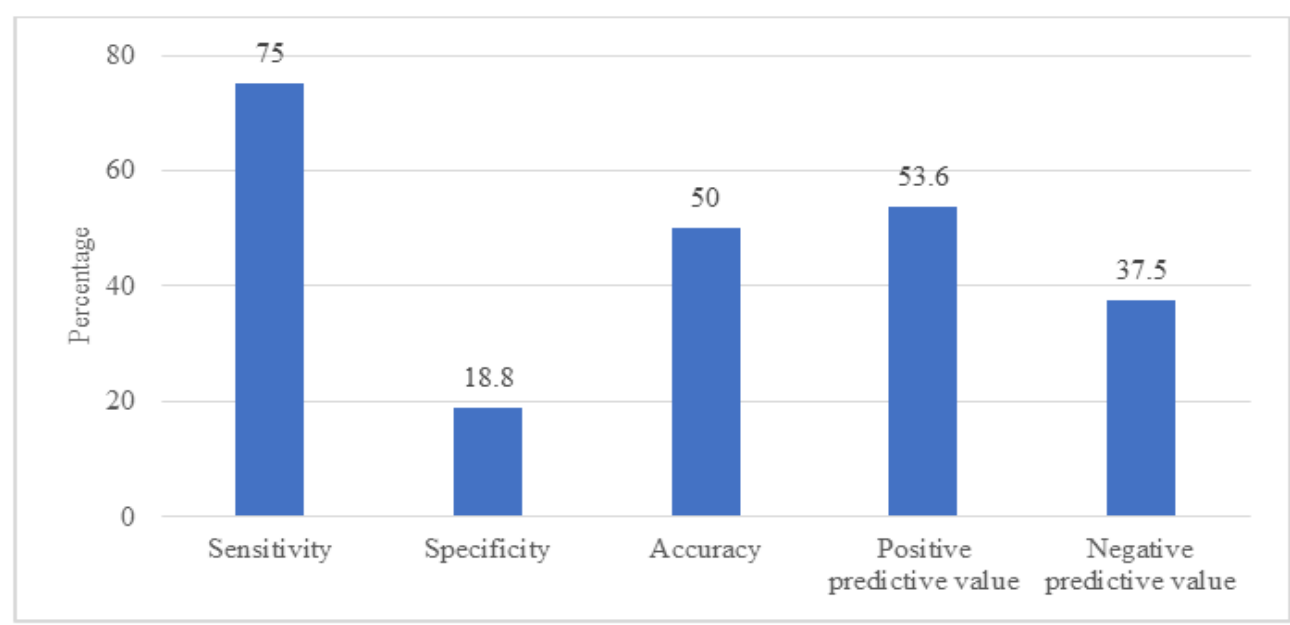

Fig-2: Bar diagram showing the sensitivity, specificity, positive and negative predictive values of the gray scale TRUS in diagnosis of prostatic lesion $(\mathrm{N}=36)$

Table-2: Transrectal Power Doppler Imaging and histopathological correlation of prostatic lesions $(n=36)$

\begin{tabular}{|l|l|l|}
\hline \multirow{2}{*}{ Transrectal Power Doppler } & \multicolumn{2}{|l|}{ Histopathological diagnosis } \\
\cline { 2 - 3 } & + ve for Malignancy & - ve for Malignancy \\
\hline Suspected for Malignant & 18 & 4 \\
\hline Suspected for benign & 2 & 12 \\
\hline
\end{tabular}




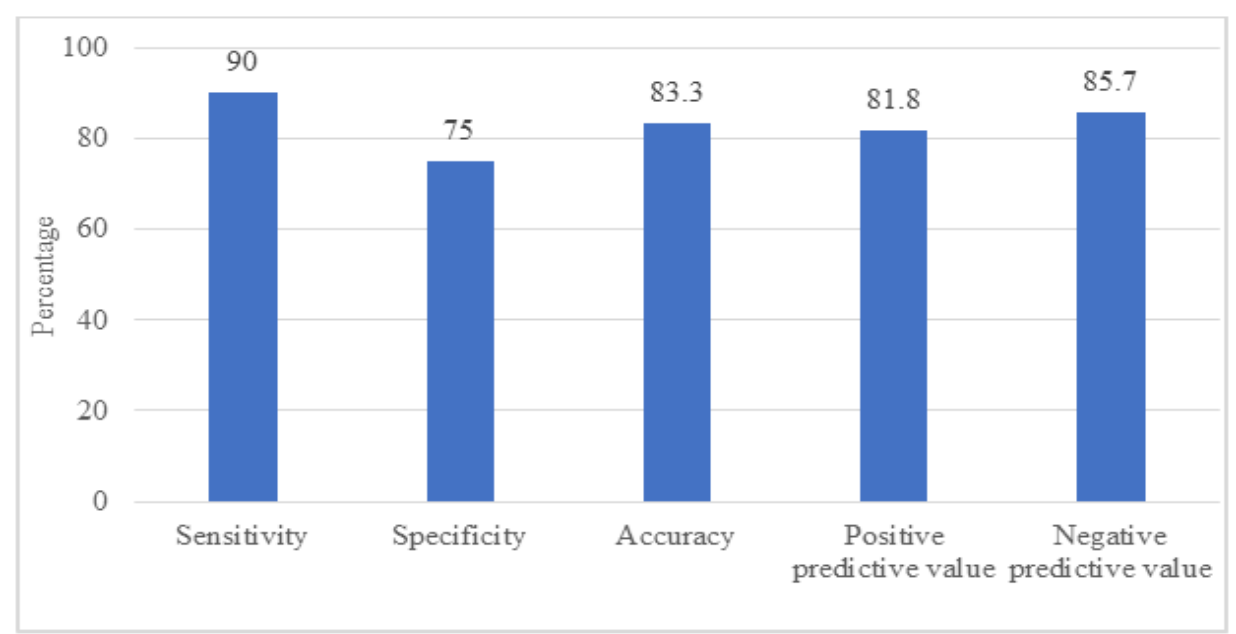

Fig-3: The Sensitivity, specificity, positive and negative predictive values of transrectal Power Doppler in diagnosis of prostatic lesions

Table-3: Sensitivity, accuracy, positive and negative predictive values of transrectal sonographic modality- gray scale \& Power Doppler sonography in the detection of prostatic cancer $(n=36)$

\begin{tabular}{|l|l|l|l|l|l|}
\hline & \multicolumn{4}{|c|}{ Values of validity test for transrectal gray scale and Power Doppler sonography } \\
\hline Transrectal sonography & sensitivity & Specificity & Accuracy & Positive predictive value & Negative predictive values \\
\hline Gray scale & 75 & 18.8 & 50 & 53.6 & 37.5 \\
\hline Power Doppler & 90 & 75 & 83.3 & 81.8 & 85.7 \\
\hline
\end{tabular}

\section{DisCUSSION}

To decrease the mortality caused by prostate cancer much attention has given to its early detection. The development of technologically advanced transrectal ultrasonogram (TRUS) examination has allowed the earlier detection of prostate cancer. Although a high level of prostatic specific antigen (PSA) can increase suspicion for prostate cancer, even high levels and abnormal findings at transrectal gray scale yield unspecific diagnoses and cannot identify all patients with prostate cancer. Many patients of prostatic lesions undergo unnecessary biopsy. In this situation, effects have been made to detect prostate cancer more effectively and reduce unnecessary biopsy. Most prostate cancers originating in the peripheral zone and visible on transrectal sonography (TRUS) were hyper vascularized on colour Doppler imaging (CD). Colour Doppler imaging has been used in the prostate to provide information additional to that from the gray scale image obtained by conventional TRUS. Power Doppler imaging was performed using the same ultrasound system as for conventional TRUS. The Power Doppler gain was set to a point below the range at which blood flow in the neurovascular bundles was identified with no background artifact. Scanning to detect flow was continued for $10 \mathrm{~min}$ in each patient. The visualization of a hypoechoic lesion in the peripheral Zone was evaluated by comparison what that of the area surrounding it. When a hypoechoic lesion contained more vessels than other peripheral zone areas, it was defined as a high velocity lesion (HVL). Equivocal and isoechoic lesions were defined as HVLS when these lesions were seen as abnormal vascular areas [6].

This observational study was carried out with an objective to describe both gray scale TRUS \& Power Doppler findings with histopathological diagnosis of prostatic lesions, evaluate the resistive index (RI) in benign and malignant prostatic lesions and also to find out the correlation between serum prostatic specific antigen (PAS) level and Power Doppler findings in different prostatic lesions. Sakarya [3] have shown in their series, the mean age of the patients with prostate cancer was $66.4 \pm 7.7$ years ranged from 45 to 70 years. Similarly, Halpern and Strup [7] have observed in their study on 251 patients, the mean age was 64.6 years ranged from 37 to 87 years. On the other hand, Lavoipierre et al., [8] has observed identical mean age of the patients having prostate cancer, which was 64.0 years with ranged from 37 to 87 years on 256 consecutive patients. In another study Shigeno [9] has observed on 278 patients with mean age 71.2 years range from 4891 years. The higher age range of their study may be due to increased life expectancy in their country. In the present study, the patients were divided into three age groups. The maximum patients were found in the age group of 60-70 years. According to histopathology $16(44.4 \%)$ cases were benign lesions and $20(55.6 \%)$ cases were malignant lesions. The mean age was 56.7 years with standard error of mean (SE) \pm 1.7 years in benign lesions with ranged from 4668 years and the maximum $8(50.0 \%)$ patients were found in the age group of 51-60 years. In malignant lesions the mean age was 59.6 years with standard error of mean $(\mathrm{SE}) \pm 1.4$ years with ranged from $46-70$ years 
and the maximum $12(60.0 \%)$ patients were found in the age group of 61-70 years. Ihee result obtained in the present study is consistent with the above mentioned studies. In this study out of 36 patients, 16 cases were benign and 20 cases were malignant lesion detected by histopathological examination. It was observed that $9(25.0 \%)$ cases were benign prostatic hyperplasia $(\mathrm{BPH}), 5(13.9 \%)$ cases were prostatitis, $2(5.6 \%)$ cases were dysplasia and $20(55.6 \%)$ case was carcinoma in histopathological evaluation. In this study the validity of gray scale TRUS in evaluation of suspected malignant lesion sensitivity $75.0 \%$, specificity $18.8 \%$, accuracy $50.0 \%$ positive predictive value $53.6 \%$ and negative predictive value $37.5 \%$. The validity of transrectal Power Doppler in evaluation of suspected malignant lesion sensitivity $90.0 \%$, specificity $75.0 \%$, accuracy $83.3 \%$, positive predictive value $81.8 \%$ and negative predictive value $85.7 \%$. Okihara [6] found the PDI characterized by high sensitivity $(98.0 \%)$ and negative predictive value $99.0 \%$ in detecting prostate cancer, which is resemble with the present study. In another study done by Sakarya et al., [3] found the sensitivity of Power Doppler was $90.0 \%$, specificity $75.0 \%$ and positive predictive value $82.0 \%$ for diagnosis of prostate cancer, which is strongly support the present study. Lavoipierre et al., [8] found the sensitivity $76.0 \%$, specificity $38.0 \%$, positive predictive value $44.0 \%$ and negative predictive value $71.0 \%$ in Power Doppler evaluation Same author found in gray scale evaluation in detecting prostate cancer the sensitivity $75.0 \%$, specificity $40.0 \%$, positive predictive value $45.0 \%$ and negative predictive value $72.0 \%$. So from the discussion we found that transrectal Power Doppler ultrasonography is better than gray scale TRUS in detecting prostate cancer.

\section{Limitations OF THE STUdy}

Small sample size due to slightly expensive and semi invasive modality. The study was conducted in one tertiary hospital, hence may not represent the whole population.

\section{Conclusion \& Recommendation}

To reduce the rate of prostate cancer detection of the prostate lesion is much more important. In the journey of detecting prostate cancer TRUS remains the first modality of choice to image and biopsy in detecting the prostate cancer. However, gray scale TRUS has a poor accuracy in detection and staging of prostate cancer. As the histopathological diagnosis of the present study significantly correlate with both gray scale TRUS and transrectal Power Doppler findings as well as the validity tests are almost identical as observed by other researchers of different study, it can be concluded that transrectal Power Doppler ultrasonogram is useful diagnostic modality in the discrimination of benign and malignant lesions in the prostate.

\section{REFERENCE}

1. Retik A, Darra CE, Wein A. (editors). Campbell's Urology, 8" edition philadelphia USA, 2002; 3001-3064

2. Rifkin MD, Sudakoff GS, Alexander AA. Prostate: techniques, results, and potential applications of color Doppler US scanning. Radiology. 1993 Feb;186(2):509-13.

3. Sakarya ME, Arslan H, Unal O, Atilla MK, Aydin $\mathrm{S}$. The role of power Doppler ultrasonography in the diagnosis of prostate cancer: a preliminary study. British journal of urology. 1998 Sep 1;82(3):386-8.

4. Neumaier CE, Martinoli C, Derchi LE, Silvestri E, Rosenberg I. Normal prostate gland: examination with color Doppler US. Radiology. 1995 Aug;196(2):453-7.

5. Turgut AT, Ölçücüoğlu E, Koşar P, Geyik PÖ, Koşar U, Dogra V. Power Doppler ultrasonography of the feeding arteries of the prostate gland: a novel approach to the diagnosis of prostate cancer?. Journal of ultrasound in medicine. $2007 \mathrm{Jul}$;26(7):875-83.

6. Okihara K, Kojima M, Nakanouchi T, Okada K, Miki T. Transrectal power Doppler imaging in the detection of prostate cancer. BJU international. 2000 Sep 1;85(9):1053-7.

7. Halpern EJ, Strup SE. Using gray-scale and color and power Doppler sonography to detect prostatic cancer. American journal of roentgenology. 2000 Mar;174(3):623-7.

8. Lavoipierre AM, Snow RM, Frydenberg M, Gunter D, Reisner G, Royce PL, Lavoipierre GJ. Prostatic cancer: role of color Doppler imaging in transrectal sonography. AJR. American journal of roentgenology. $1998 \mathrm{Jul}$; 171(1):205-10.

9. Shigeno K, Igawa M, Shiina $\mathrm{H}$, Wada $\mathrm{H}$, Yoneda $\mathrm{T}$. The role of colour Doppler ultrasonography in detecting prostate cancer. BJU international. 2000 Aug;86(3):229-33. 